\title{
PRODUCCIÓN SUBJETIVA DE SEGREGACIÓN ESCOLAR EN CHILE: un estudio cualitativo basado en "juegos de clasificación"
}

\author{
Cristian Oyarzún Maldonado \\ Universidad de Chile - UCHILE, Chile \\ Rodolfo Soto González \\ Universitat de Barcelona - UB, Espanha
}

\begin{abstract}
Resumen
En el presente artículo exponemos una investigación cualitativa que tuvo por objetivo explorar en la producción de subjetividades que configuran y justifican la segregación escolar en Chile, un caso extremo de sistema escolar regulado por mecanismos de mercado. Para indagar en la posible producción de subjetividades relacionadas con la segregación escolar, se efectuó un uso adaptado de los "juegos de clasificación” de la Sociología Pragmática, una técnica que genera información mediante los juicios que actores sociales realizan sobre objetos de la realidad. Así, el objeto de análisis fue la comprensión de directivos y familias acerca de afiches de publicidad, previamente identificados como representativos por medio de una técnica de estadística multivariable y que en este caso han sido conceptualizados como fabricaciones, es decir, artefactos culturales que representan versiones de las escuelas y se fundan en subjetividades que dotan de sentido su puesta en acto. Los hallazgos revelan el despliegue de relatos que justifican y aceptan dinámicas de segregación escolar en base a características socioeconómicas y personales de los estudiantes. Estos resultados son analizados en función de las características de la sociedad chilena y de la influencia de los mecanismos del modelo de mercado escolar vigente.
\end{abstract}

Palabras clave: Segregación escolar; Mercado escolar chileno; Metodología cualitativa; Sociología pragmática, Subjetividad.

\begin{abstract}
In this article we present a qualitative research that aimed to explore the production of subjectivities that configure and justify school segregation in Chile, an extreme case of a school system regulated by market mechanisms. To investigate the possible production of subjectivities related to school segregation, an adapted use of the "classification games" of Pragmatic Sociology was made, a technique that generates information through the judgments that social actors make about objects of reality. Thus, the object of analysis was the understanding of managers and families about advertising posters, previously identified as representative by means of a multivariate statistical technique and which in this case have been conceptualized as fabrications, that is, cultural artifacts that represent versions schools and are based on subjectivities that give meaning to their enactment. The findings reveal the unfolding of stories that justify and accept dynamics of school segregation based on socioeconomic and personal characteristics of the students. These results are analyzed based on the characteristics of Chilean society and the influence of the mechanisms of the current school market model.
\end{abstract}

Keywords: School segregation; Chilean school market; Qualitative methodology; Pragmatic sociology, Subjectivity. 


\section{Introducción}

Los sistemas educacionales contemporáneos tienen como objetivo garantizar el acceso a oportunidades de aprendizaje socialmente significativas (UNESCO, 2017). Esta meta de política pública implica no sólo alcanzar niveles suficientes de cobertura, sino también generar sistemas educacionales inclusivos, orientados a lograr el desarrollo académico y socioemocional de todos los estudiantes, presenten o no discapacidades, e indistintamente de su género, etnia y/o nivel socioeconómico [NSE] (Ainscow; Booth; Dyson, 2006; Krüger, 2019).

Sin perjuicio de lo anterior, las políticas para desarrollar sistemas educacionales inclusivos afrontan problemáticas concretas, siendo la segregación socioeducativa una de las más relevantes (Bonal; Bellei, 2018). Específicamente, la segregación escolar refiere a la distribución desigual de estudiantes en los centros educativos según sus características personales y/o sociales (Murillo; Martínez-Garrido, 2017). La evidencia empírica sostiene que la segregación escolar se relaciona con consecuencias negativas, tales como: fuerte incidencia del NSE de las escuelas en el logro académico, fenómeno conocido bajo el nombre de "efecto par"; asociaciones significativas entre la composición socioeconómica y otras variables que, indirectamente, afectan los aprendizajes, por ejemplo, menores expectativas ante los procesos educativos de comunidades desfavorecidas; y bajas probabilidades de producir dinámicas de integración social mediante la convivencia al interior de la escuela (Epple; Romano, 1998; Dupriez; Dumay, 2006; Mickelson; Nkomo, 2012).

En cuanto a sus causas, la segregación escolar es provocada por factores exógenos, alusivos a la segregación residencial, y factores endógenos, referidos al diseño de los sistemas educacionales (Duk; Murillo, 2019). Al respecto, Bonal y Bellei (2018) afirman que la estructura residencial constituye la causa principal de la segregación a nivel de las escuelas, mientras que características institucionales, como el uso de prácticas selectivas y mecanismos de mercado -libre elección y participación de proveedores privados-, pueden incrementarla sustancialmente. Este es el caso de Chile, país que exhibe una elevada segregación residencial en sus grandes zonas urbanas (PNUD, 2016), al mismo tiempo que sobresale por el desarrollo de un sistema educacional fuertemente estructurado en base a mecanismos de mercado, todo lo cual ha favorecido la consolidación de una intensa segregación escolar (OCDE, 2017).

La evidencia empírica sobre segregación escolar en Chile proviene -mayormente- de investigaciones cuantitativas, las que han aportado en estimar la magnitud de este fenómeno y en identificar sus factores causales. Además de constatarse elevados niveles de segregación escolar, la investigación reciente demuestra que elementos institucionales -libre elección, privatización y cobro de tarifas- exacerban significativamente la segregación residencial (Valenzuela; Bellei; De los Ríos, 2014; Santos; Elacqua, 2016; Gutiérrez, 2019). De manera contrastante, la dimensión subjetiva de la segregación escolar en Chile es aún desconocida, siendo su principal antecedente las investigaciones cualitativas sobre school choice, que han ilustrado las racionalidades desplegadas por familias de clases bajas y medias para elegir un centro educativo (Bellei et al., 2018). 
En este contexto, el presente artículo reporta una investigación cualitativa que exploró en la producción de un soporte subjetivo que configura y justifica la segregación escolar en Chile. Si ocurre y cómo ocurre esto, desde la perspectiva de actores educativos relevantes, constituye el objeto de análisis de este reporte de investigación. Considerando el objetivo trazado, se elaboró un dispositivo de investigación basado en los "juegos de clasificación" de la Sociología Pragmática (Boltanski; Thévenot, 1983), una técnica que, a partir de la exposición de cierto material visual, "genera información sobre las formas en que las personas comunes y corrientes nombran los objetos de la realidad y se figuran la sociedad" (Barozet; Mac-Clure, 2014, p. 198). Puntualmente, en este trabajo de investigación se utilizó imágenes de afiches de publicidad exterior que grafican dos tipologías de escuelas representativas de una zona urbana-metropolitana, las que previamente fueron identificadas mediante una técnica de estadística multivariable, presentándose como estímulos para elicitar conversaciones con padres y directivos de centros educativos pertenecientes a grupos socioeconómicos bajos y medios.

$\mathrm{El}$ artículo está organizado en tres partes. Primeramente, se exponen antecedentes contextuales sobre el mercado escolar y la segregación socioeducativa en Chile, a la vez que se describen aspectos teóricos referidos a la Sociología Pragmática. En segundo lugar, es detallado el procedimiento metodológico aplicado y en la tercera parte son presentados los principales hallazgos. En la sección final, se discuten los resultados en cuanto a su aporte a la temática analizada y el alcance de la metodología aplicada para indagar en la producción subjetiva de segregación escolar.

\section{Marco teórico}

\subsection{Mercado escolar chileno y segregación socioeducativa}

Las reformas de mercado en Chile presentan dos momentos de implementación (Cornejo, 2018). El primer momento tuvo ocurrencia en la década de 1980 y corresponde a la reforma estructural del Estado impuesta por la dictadura cívico-militar que, en el ámbito de la educación escolar, incluyó un paquete de medidas como libre elección parental, financiamiento vía voucher, desregulación de la oferta privada, transferencia administrativa de las escuelas públicas desde el Ministerio de Educación hacia los municipios y, posteriormente -en democracia-, la promulgación de una ley que habilitó a las escuelas privadas subvencionadas para aplicar tarifas a las familias (Verger; Zancajo; Fontdevila, 2018). La configuración descrita es la de un mercado privado, en donde el principal criterio de elección refiere al coste entre un conjunto de proveedores públicos y privados (Felouzis; Maroy; Van Zanten, 2013).

Por su parte, el segundo momento surge como respuesta a los movimientos estudiantiles del año 2006 (Inzunza et al., 2019) y consistió en un proceso de perfeccionamiento del modelo original que, en lo específico, implicó la promulgación de una serie de leyes1 que introdujeron medidas de new public management y rendición de cuentas de alto impacto (Cornejo et al., 2015; Parcerisa; Falabella, 2017). Adicionalmente, en el año 2015 se aprobó la denominada Ley de Inclusión que elimina de manera gradual el lucro, el financiamiento 
compartido y la selección de estudiantes, pero sin suprimir los principales mecanismos de mercado -subsidio per cápita, privatización y libre elección- (Carrasco; Gunter, 2018; Sisto, 2019). Esta segunda forma organizativa se asemeja mayormente a un cuasi-mercado, una configuración que incluye escuelas gratuitas -públicas y privadas-, financiadas a través de subvención, y en la cual se espera que los resultados académicos derivados de evaluaciones estatales sean el criterio decisivo de elección (Felouzis; Maroy; Van Zanten, 2013). Siguiendo a Stephen Ball (2000), las regulaciones de un cuasi-mercado pueden interpretarse como tecnologías performativas que constriñen a los agentes a partir de evaluaciones y desempeños medibles.

Entre los efectos vinculados con la aplicación de reformas de mercado se halla la elevada segregación socioeducativa registrada en las escuelas chilenas. Específicamente, las investigaciones recientes muestran que Chile dispone de uno de los sistemas escolares más segregados de América Latina (Murillo; Martínez-Garrido, 2017; Krüger, 2019), cuyos índices exceden a la segregación socioeconómica de los barrios (Valenzuela; Bellei; De los Ríos, 2014). Esta dinámica se explica por factores institucionales relativos al financiamiento compartido, la selección de estudiantes y las preferencias parentales (Mizala; Torche, 2012; Santos; Elacqua, 2016; Gutiérrez, 2019). Como consecuencia de lo descrito, se tiene que "el desempeño escolar en Chile depende más de la condición socioeconómica de sus estudiantes que de la calidad de los servicios educativos que entregan las escuelas o de los tipos de escuela" (OCDE, 2017, p. 61). En cuanto a la evidencia cualitativa, estudios sobre prácticas de elección de escuela plantean que las familias de clase media buscan incorporarse a espacios educativos cerrados y homogéneos (Canales; Bellei; Orellana, 2016; Rojas; Falabella; Leyton, 2016), mientras las clases bajas pretenden -dentro de sus posibilidadesevitar los centros que a su juicio tienen menor prestigio o constituyen riesgos sociales (Gubbins, 2013; Córdoba, 2014; Bellei et al., 2016; Bonal; Verger; Zancajo, 2017).

\subsection{Sociología Pragmática y Juegos de Clasificación}

La presente investigación se basó en un uso adaptado de los "juegos de clasificación". Este dispositivo metodológico proviene de la Sociología Pragmática, un programa de investigación que reconoce en los actores sociales competencias cognitivas y morales que les permiten evaluar y elaborar críticas sobre la realidad social, entendiéndose como competencias aquellos esquemas mentales que sustentan la capacidad de los actores para producir críticas aceptables y/o justificaciones normativas en una situación concreta (Boltanski, 2011).

Desde esta perspectiva, los actores sociales no se encuentran absolutamente constreñidos por una estructura que determina sus acciones y disposiciones, sino que desarrollan principios valorativos disímiles entre participantes y/o juicios que pueden fundarse en principios diferentes de los oficialmente proclamados. De este modo, "el mundo social no parece ser el sitio de dominación soportado pasiva e inconscientemente, sino un espacio atravesado por una multiplicidad de disputas, críticas, desacuerdos e intentos de restablecer acuerdos locales 
que siempre son frágiles"2 (Boltanski, 2011, p. 27). Conforme a lo expuesto, la Sociología Pragmática fija su objeto de estudio en el conocimiento práctico que los individuos producen para calificar y justificar sus acciones en situaciones de la vida cotidiana (Boltanski; Thévenot, 1983; Boltanski, 2011).

En este marco, los "juegos de clasificación" constituyen una metodología originalmente desarrollada para estudiar la estructura socio-ocupacional, la que consiste en un ejercicio de simulación donde los participantes evalúan y califican de forma directa a otros actores y objetos sociales representados en viñetas, siendo sus principales propósitos acceder a los esquemas mentales que justifican la elección del material visual presentado e interpretar los argumentos derivados de las cualificaciones (Boltanski; Thévenot, 1983). Consecuentemente, "este dispositivo metodológico hurga en las generalizaciones habituales, las denominaciones más populares, el sentido común aplicado cotidianamente y los prejuicios sociales que se utilizan al categorizar a las personas y objetos de la sociedad" (Mac-Clure et al., 2015, p. 7).

\section{Metodologia}

La evidencia empírica aquí expuesta emerge de un diseño metodológico de tipo cualitativo. De forma opuesta a los métodos cuantitativos, que habitualmente emplean procedimientos predefinidos e invariables, los abordajes cualitativos ubican al investigador como artífice de las técnicas de producción de datos y, por ende, estas pueden desarrollarse de manera flexible, adaptándose al objeto de estudio (Maxwell, 2013). Es el caso de la presente investigación, ya que para indagar en la producción subjetiva de segregación fue elaborado y aplicado un dispositivo metodológico inspirado en los "juego de clasificación".

El dispositivo creado fue denominado "juego de clasificación de afiches escolares" y deriva de la aplicación de una técnica de estadística multivariada que permitió identificar afiches prototípicos de escuelas municipales y particulares subvencionadas de la Provincia de Santiago. Consiguientemente, el material gráfico resultante fue ocupado en entrevistas y focus group con el propósito de conocer las interpretaciones de padres y directivos.

Cabe indicar que, siguiendo la teoría de Stephen Ball (2000), los afiches de publicidad han sido conceptualizados como fabricaciones, es decir, "versiones de una organización (o persona) que no existe - no están "fuera de la verdad", pero tampoco se refieren a una simple verdad o a descripciones directas-, producidas para responder a las disciplinas del mercado y la rendición de cuentas" (p. 9). Además, investigaciones sobre marketing escolar en sistemas de mercado han ilustrado dinámicas de competencia de segundo orden -captación de estudiantes aventajados- y estrategias de segmentación del mercado por tipo de público (e.g. Lubienski, 2007; Jabbar, 2015; Zancajo, 2018).

En particular, el material gráfico ocupado proviene de un estudio previo (Oyarzún, 2021), el cual utilizó una muestra representativa de 290 afiches de escuelas urbanas municipales y particulares subvencionadas- de la Provincia de Santiago. En primer lugar, los afiches fueron analizados de forma inductiva, codificándose en una hoja de registro todos los 
mensajes -textos e imágenes-para luego asignarles un nombre y una definición operacional. Como resultado de este primer procedimiento se registró un número total de 36 códigos, asignándose el valor 1 a la presencia del código y 0 ante su ausencia. En segundo lugar, teniéndose tabulados todos los afiches, se efectuó un Análisis de Clases Latentes (ACL). Puntualmente, el ACL es una técnica de estadística multivariada que detecta el número de Clases o grupos relativamente homogéneos de una muestra heterogénea de sujetos, esto en base a un conjunto de variables de respuesta observadas (Finch; Bronk, 2011). En este caso, los grupos latentes corresponden a los afiches prototípicos detectados y las variables de respuesta observadas son los códigos de contenidos registrados en cada afiche de la muestra.

Los resultados del ACL indicaron que una solución de dos Clases o grupos provee el mejor ajuste a los datos, esto según diferentes índices de ajuste y test de verosimilitud detallados en la tabla 1:

Tabla 1: Indicadores de bondad de ajuste para el Análisis de Clases Latentes (N=290).

\begin{tabular}{|l|c|c|c|c|c|}
\hline Número de clases & Loglikelihood & AIC & BIC & V-LMR p valor & LMR LRT p valor \\
\hline 1 Clase & -3725.924 & 7523.848 & 7541.801 & - & - \\
\hline 2 Clases & $\mathbf{- 3 3 9 1 . 7 2 3}$ & $\mathbf{6 9 2 9 . 4 4 6}$ & $\mathbf{6 9 6 5 . 8 5 1}$ & $\mathbf{1 8 . 6} \boldsymbol{p}=\mathbf{0 . 0 0} * * *$ & $\mathbf{6 6 5 . 2 3} p=\mathbf{0 . 0 0 * * *}$ \\
\hline 3 Clases & -3316.561 & 6853.123 & 6907.980 & $4.1 \quad \mathrm{p}=1.00$ & $149.610 \mathrm{p}=1.00$ \\
\hline
\end{tabular}

$* * * \mathrm{p}-\mathrm{val}<0.01, * * \mathrm{p}-\mathrm{val}<0.05$

Criterio de información de Akaike [AIC], Criterio bayesiano de información ajustado por tamaño de la muestra [BIC], Test de razón de verosimilitud ajustada Vuong-Lo-Mendell-Rubin [V-LMR], Test de razón de verosimilitud ajustada Lo-Mendell-Rubin [LMR-LRT]. El modelo destacado muestra un mejor ajuste a los datos.

Fuente: elaboración propia.

Los códigos o contenidos de las dos clases detectadas son graficados en la figura 1. Esta representación muestra en el eje horizontal los 36 códigos posibles en la conformación de un afiche prototípico, en tanto el eje vertical señala la probabilidad de presencia - de $0 \%$ a 100\% - para cada uno de los códigos en las clases identificadas. Con más detalle, la Clase 1 es señalizada con la línea roja y agrupa 180 casos de la muestra $(61,7 \%)$, mientras la Clase 2, indicada con la línea azul, abarca 110 (38,3\%). Para lograr mayor certeza en la distribución de los códigos se optó por considerar aquellos con una probabilidad de presencia igual o superior a 35\%. Por ello, se fijó una línea discontinua trazada horizontalmente que permite observar aquellos códigos con una presencia probable de a lo menos 35\%. De este modo, la Clase 1 incluye un sólo código: "excelencia académica"; mientras la Clase 2 tiene siete códigos con probabilidades de presentarse: "actividades extraprogramáticas", "uso de tecnología", "imágenes de estudiantes", "JEC"3, "inglés", "PIE"4 y "SEP"5. Resulta importante señalar que, según el análisis estadístico, las clases detectadas no están asociadas a los tipos de dependencia. 
Figura 1: Probabilidad de presencia de los códigos en cada una de las clases detectadas por el ACL.

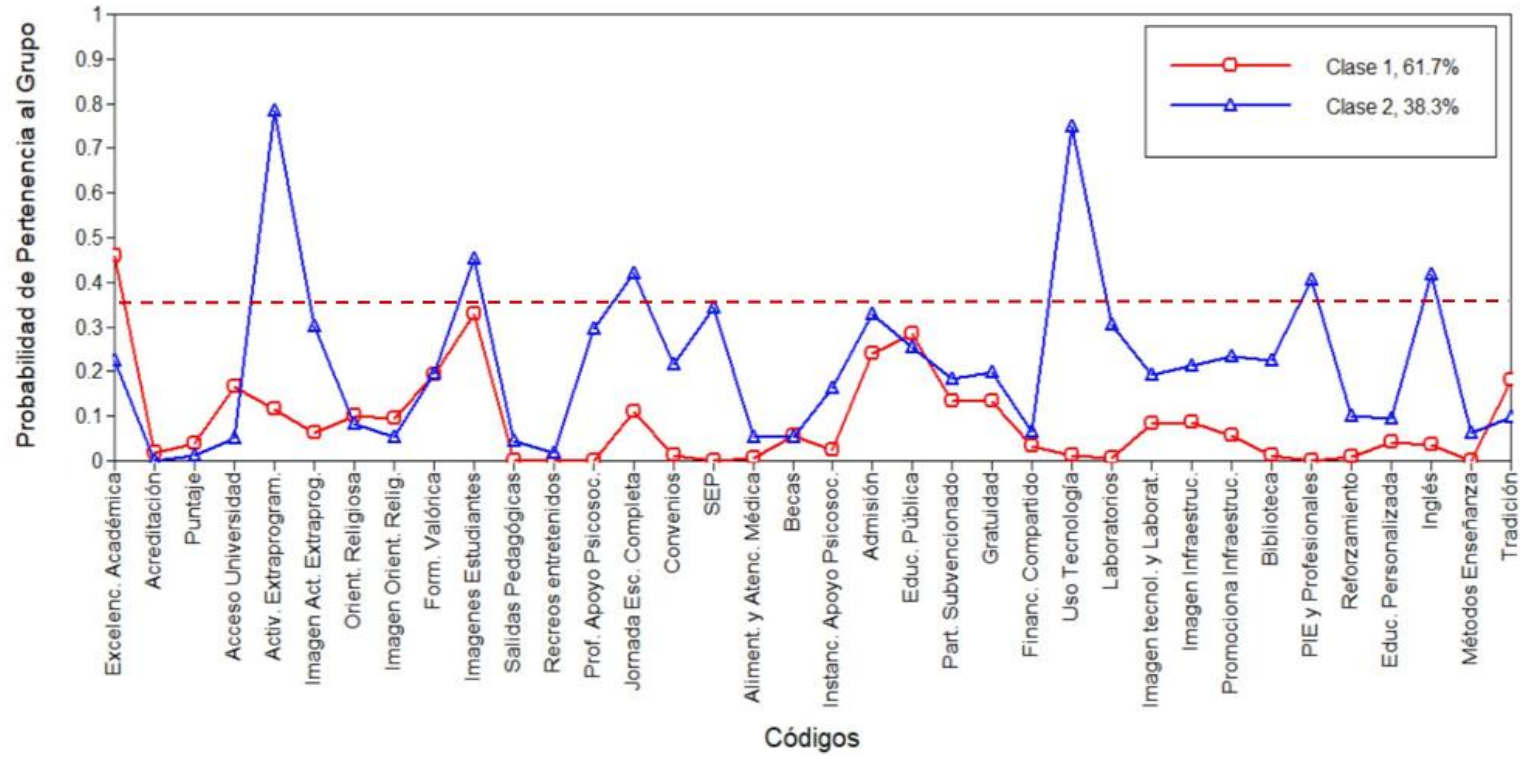

Fuente: elaboración propia.

En la figura 2 se presentan ejemplos de ambas tipologías de afiches o Clases detectadas. Cabe mencionar que, en el caso de la Clase 1, se añadió una variante que incorpora el código "imágenes de estudiantes", esto considerando que, en la Clase 1, dicho código es el segundo en términos porcentuales y, también, con el propósito de explorar eventuales diferencias en las respuestas de los participantes.

Habiéndose identificado el material gráfico requerido, el procedimiento de aplicación del dispositivo fue el siguiente: primeramente, un investigador proporcionó a los participantes un set de seis afiches, tres de cada Clase. En segundo lugar, solicitó a los participantes que clasifiquen los afiches en grupos que a su juicio dispusieran de características comunes y, luego, pidió que le asignarán nombres que desde su punto de vista fuese representativo de los contenidos. Todo esto se ejecutó sin entregar información sobre la escuela ofertada en el afiche, por ejemplo, sobre el tipo de dependencia o lugar de emplazamiento. En tercer lugar, a través de focus group y entrevistas se instó a que los participantes enunciaran los criterios utilizados para cualificar los afiches y sus contenidos. 
Figura 2: Ejemplos de afiches representativos de la Clase 1 y 2 utilizados en focus group y entrevistas ${ }^{6}$.

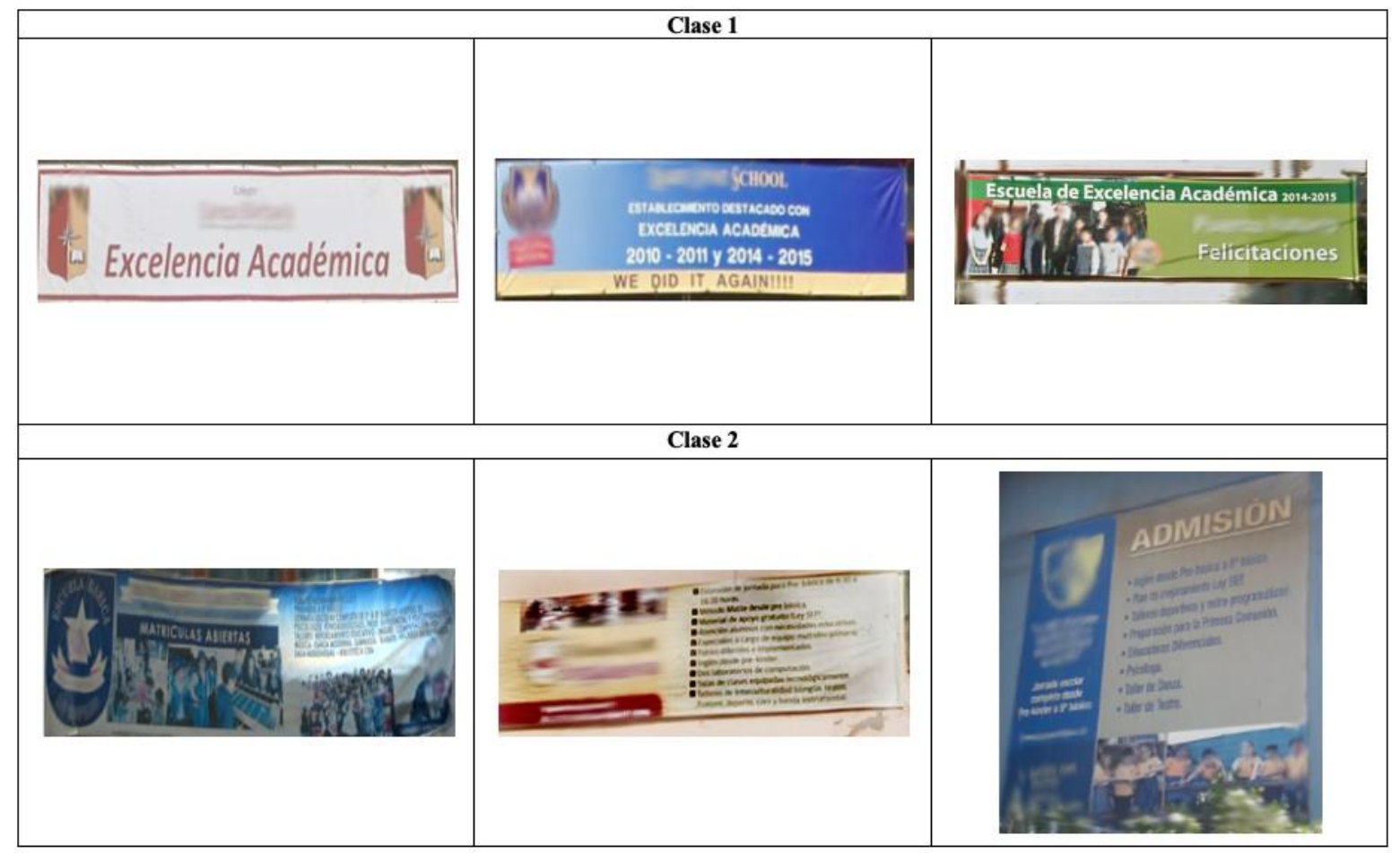

Fuente: elaboración propia.

Los participantes fueron seleccionados mediante la estrategia llamada selección decidida (Maxwell, 2013), que consiste en escoger de forma intencionada contextos y actores sociales determinados, los cuales disponen de información particularmente atingente para los objetivos de investigación y que no podrían hallarse por medio de otras fuentes. En este sentido, las perspectivas de apoderados y directivos son especialmente relevantes para acceder a la eventual producción subjetiva de segregación, ya que estos ejercen roles estratégicos en procesos claves como la elección de escuela y la definición de una oferta educativa.

Por su parte, el tamaño de la muestra fue establecido en base a la saturación teórica, un criterio para determinar el momento en el cual dejar de muestrear un grupo, investigar un tema o elaborar un eje temático, que es aplicado cuando los datos recopilados ya no proporcionan información significativa en relación con aquella previamente registrada (Creswell, 2014). De este modo, la muestra estuvo integrada por 27 participantes, 17 apoderadas y 10 directivos, que se distribuyeron en tres focus group, dos con cuatro apoderadas del sector municipal y uno con cinco apoderadas del sector particular subvencionado, y el resto en entrevistas individuales. Cabe puntualizar que, los participantes provienen de grupos socioeconómicos bajos y medios, de escuelas ubicadas en posiciones disímiles de sus mercados locales y de diferente dependencia, todo esto con el propósito de 
contrastar sus puntos de vista. Además, se intencionó el uso de focus group y entrevistas a fin de identificar eventuales variaciones en la respuesta subjetiva de los participantes ante técnicas distintas.

La técnica de análisis empleada fue el análisis de contenido, aplicado a los 17 textos resultantes de las transcripciones de los focus group y las entrevistas. En términos procedimentales, el análisis de contenido fue realizado inductivamente a partir de la lectura sistemática de los textos, con el propósito de codificar sus unidades básicas de significado (Maxwell, 2013). Tomando como base las unidades básicas de significado, se efectuó un análisis conjunto de los códigos que permitió identificar tipologías, es decir, unidades mayores de significado (Ibáñez, 1979). Estas tipologías, como elaboraciones realizadas a partir del análisis de los textos, permitieron captar el sentido que atraviesan las distintas opiniones, juicios y posiciones expresadas de manera singular por cada participante (Conde, 2015). El análisis del material cualitativo fue llevado a cabo por intermedio del software Atlas.ti.

\section{Resultados}

\subsection{Dinámica de las clasificaciones}

Aun cuando los participantes provienen de diversas comunidades y ejercen roles diferentes, la dinámica de clasificación registrada fue estable y coherente en términos de los sentidos atribuidos, evidenciándose una gramática social compartida entre los actores educativos. Con más detalle, la mayoría de los participantes identificó de forma expedita los dos grupos de afiches conformados por la Clase 1 y la Clase 2, respectivamente, a excepción de una apoderada, quien proporcionó una clasificación distinta a la predominante.

En algunas ocasiones los participantes no enunciaron nombres específicos, centrándose en definir y describir lo que desde su perspectiva significaba cada grupo de afiches. Así, las definiciones y descripciones entregadas revelaron dos unidades de sentido claramente delimitadas. Por una parte, la Clase 1 fue interpretada como la oferta de un centro educativo que ha alcanzado logros académicos certificados por el Ministerio de Educación, lo que se verifica con la tenencia del reconocimiento llamado "excelencia académica". Por otra parte, la Clase 2 fue decodificada como la oferta de una institución escolar que, de forma compensatoria, al adolecer de la "excelencia académica", concentra su promoción en servicios orientados a satisfacer variadas necesidades sociales y recreativas, que no están vinculados de manera directa con el ámbito académico.

Adicionalmente, las clasificaciones y descripciones propuestas no aparecen relacionadas con el tipo de dependencia administrativa de las escuelas oferentes. Al respecto, la única excepción tuvo ocurrencia en el focus group integrado por madres del sector particular subvencionado, quienes, luego de identificar la Clase 1 y la Clase 2, manifestaron una diferenciación entre aquellos afiches que a su juicio representaban escuelas municipales y particulares subvencionadas, evidenciándose una valoración negativa hacia las primeras. 
La espontaneidad y consistencia de las clasificaciones registradas, revela una correspondencia significativa entre el contenido de los afiches y el conocimiento práctico de los actores consultados. En otras palabras, los afiches y sus contenidos representan categorías típicas del cotidiano de la "escuela" y de ellas devienen asociaciones nítidas acerca de tipologías de escuela y su público objetivo:

[...] Es que acá [indica el afiche de excelencia académica]. Si mi hijo, no es de calificación siete o de cinco hacia arriba, para mi va a estar complicado que lo reciban en este colegio, tal vez si tienen ellos tanto énfasis en las calificaciones. Entonces yo tendría que dejar este de lado [afiche de excelencia académica] y buscar más esto [afiche de servicios], de integración, porque mi hijo "no es de siete”, le cuesta un poco más, es más desordenado, es más disperso, no sé [risas]. Entonces yo ahí tendría que ver. ¡Claro que son distintas! [las tipologías de escuelas representadas en los afiches]. (G1, Apoderadas, Municipal)

Considerando lo antes dicho, las dos tipologías de oferta escolar identificadas enmarcan el análisis de contenido que a continuación expondremos, en donde se da a conocer detalladamente el contenido de las interpretaciones efectuadas por los actores educativos.

\subsection{Análisis de contenido}

Los hallazgos del análisis de contenido serán expuestos de forma esquemática mediante dos tipologías: "Oferta de Excelencia Académica" y "Oferta de Servicios". Cada tipología de oferta incluye tres categorías que detallan qué significa, para quién está dirigida y cuál es su valor añadido o utilidad percibida por los participantes.

\section{Oferta de Excelencia Académica}

\section{Una oferta que garantiza buenos resultados}

La "excelencia académica" es comprendida en función del significado atribuido por apoderados y directivos. En este sentido, los actores que interactúan en el mercado escolar manifiestan que la "excelencia académica" alude a "resultados académicos sobresalientes", ya sea en calificaciones o altos desempeños en las pruebas $\operatorname{SIMCE}^{7}$ y $\mathrm{PSU}^{8}$ :

[...] yo siento que al ser como un afiche, que trata de captar un público, que son los apoderados [...] para los apoderados la excelencia académica se relaciona sólo con el rendimiento escolar. Entonces, yo siento, que la idea es como captar ese público. Como esa mirada, como que son colegios que tienen un buen rendimiento [...] (E10, Integrante equipo directivo, Municipal)

Asumiendo una lógica comercial, los participantes consideran que es factible una instrumentalización de este rótulo, con el propósito de proyectar una imagen de prestigio 
vinculada a un rendimiento académico elevado. Al respecto, las conversaciones registradas indican que los actores tienen conocimiento sobre la definición oficial de "excelencia académica" y de los requerimientos formales que se requieren para su asignación. No obstante, comprenden que, cuando este reconocimiento es empleado en un afiche de publicidad, adquiere una significación ligada con el logro de altos niveles de aprendizaje reflejados en "buenas" calificaciones:

M: La SNED 9 no solamente mide SIMCE, mide todo, mide otros indicadores de calidad...

E: Claro, hay otros indicadores, son seis.

M: Claro, hay desempeño, organización de la escuela, son seis en total...

E: Pero ¿cómo lo entenderá un padre o un ciudadano común?

M: En las notas y en el aprendizaje (E11, Directora, Particular Subvencionado)

En este marco, la excelencia se constituye en un significante vacío que, frecuentemente, adquiere significado en la imagen de una escuela de corte academicista, lo cual, desde la óptica de los actores consultados, implica una elevada exigencia en el rendimiento académico y una fuerte disciplina escolar:

[la excelencia académica] es una exigencia en las notas, en el comportamiento de los niños, en el uniforme, en todo. (G2, Apoderadas, Municipal)

M: En estos colegios les exigen mucho, mucho [habla desde su experiencia personal con escuelas de excelencia académica]

$E:$ ¿en las calificaciones, en la disciplina?

M: las calificaciones, la disciplina, la vestimenta, en el orden (E3, Apoderada, Particular Subvencionado)

Consecuentemente, a partir de la tenencia de un reconocimiento oficial del Estado, la oferta de "excelencia" permite construir y divulgar una imagen institucional de prestigio académico, la cual aseguraría orden en el ámbito de la disciplina escolar y resultados sobresalientes en las asignaturas principales. Esta concepción de la oferta conlleva una segmentación del "público" que, como ilustraremos en lo que sigue, refiere a un grupo selecto de estudiantes, receptivos a altos niveles de exigencia y productivos en cuanto a su desempeño académico.

\section{Una imagen que autoselecciona: el consumidor de excelencia académica}

Los afiches son fabricaciones que construyen imágenes de escuela. Considerando esta premisa, la propuesta detrás de la excelencia es interpretada como la de una escuela que intenta atraer estudiantes de alto rendimiento y capaces de adscribir a las exigencias inherentes a esta propuesta. Ambos aspectos, permitirían al estudiante y su familia incorporarse a este tipo de instituciones. En caso contrario, deberán buscar otra alternativa en el mercado de las escuelas, pues la incapacidad de tolerar las exigencias implica que ese 
espacio educacional no es apto para ellos. En otras palabras, la construcción de esta imagen corporativa, conocida por su "exigencia" y "alto rendimiento", opera en el plano simbólico generando un clivaje que señaliza quienes podrían adaptarse mejor a este tipo de escuela:

Al tener la excelencia académica, no puedes mandar un niño que sea hiperactivo a un colegio así, porque no van a tener como ayudarlo, porque ellos [las escuelas de excelencia académica] exigen que aprendan [...] (E3, Apoderada, Particular Subvencionado)

Acá [oferta de excelencia académica], un niño con necesidades educativas especiales puede pasarla mal, porque aquí [escuelas de excelencia académica] exigen bastante y esos estudiantes requieren otros apoyos, tienen logros a partir de su capacidad particular [...] (E14, Directora, Municipal)

De este modo, la oferta de excelencia intenta atraer a quienes tienen el potencial de alcanzar un rendimiento sobresaliente y adaptarse a dicho ambiente de exigencias. Estas características, develan por oposición quienes tendrían dificultades para acceder a estos ambientes escolares o, abiertamente, quienes no están llamados a ser parte de ellos, tal como en los fragmentos presentados se alude a estudiantes con necesidades educativas especiales. Con todo, la fabricación de estas imágenes corporativas induciría dinámicas de autoselección, como se expresa en la siguiente cita:

Este afiche [que promociona excelencia académica y cuyo nombre se encuentra en idioma inglés] no está enfocado en la gente común, porque tú ves lo que dice [indica el mensaje de excelencia académica] y además tiene un nombre en inglés, entonces sube su nivel y está dirigido a otro tipo de gente. (G3, Apoderadas, Particular Subvencionado)

La cita expuesta no señala -explícitamente- asociaciones entre grupos socioeconómicos y mayores niveles de "excelencia académica", pero si permite inferir que la concepción de "excelencia académica" difundida en los afiches provoca dinámicas de autoselección que aportan a la segregación de los mercados locales en que se emplazan las escuelas. Planteado de otro modo, cada mercado local, ya sea a nivel de barrios o villas, se halla estratificado en base a distintas modalidades de la oferta escolar. Es así como el uso de afiches que promocionan "excelencia académica" es comprendido como una disposición de los proveedores a construir imágenes de prestigio institucional, cuyo propósito es generar una constitución social y académica aventajada para alcanzar mejores resultados:

[...], la excelencia académica es un plus, pero además ese plus se logra porque tienes un grupo de personas que acceden a dicho colegio de manera aspiracional y que tienen algunas características socioeconómicas o socioculturales que le permiten serlo, sin necesidad de que el colegio tenga una gran experiencia o una gran capacidad instalada [...] Que pasa mucho en escuelas que dicen "nosotros tenemos una gran experiencia", "nosotros somos técnico pedagógicamente una cuestión maravillosa” pero, en el fondo, lo único que explica sus resultados es su 
contexto [...] con los alumnos que tienen, con las familias que tienen, obviamente van a tener esos resultados [...] (E12, Directivo institucional, Particular subvencionado)

\section{El valor agregado: alto desempeño y ascenso social}

En cuanto al valor agregado o utilidad atribuida por los participantes, los relatos analizados evidencian dos beneficios atribuidos a la oferta de excelencia académica: asegurar un alto desempeño y, a partir de ello, aumentar las posibilidades de ascenso social.

Sobre el primer aspecto, los actores educativos expresan una certeza referida a la capacidad de una escuela rotulada como de "excelencia" para asegurar mejores rendimientos entre los estudiantes:

[...] es probable que tengan mejores resultados los de excelencia académica que los de acá [en referencia a los afiches que muestran múltiples servicios] [...] (E13, Directivo institucional, Particular subvencionado)

Esta certeza se arraiga en el carácter exógeno de la "excelencia académica", rótulo asignado por el Ministerio de Educación. El origen estatal de este reconocimiento es decodificado por los participantes como un indicador de la calidad de la oferta educativa, pues el Estado opera como la entidad que regula y certifica la oferta disponible en el mercado de escuelas:

Porque un buen logro, una buena medalla en el pecho es decir "nosotros tenemos la excelencia académica", quiere decir que en el área académica nuestros niños estudian y aprenden [...] (E9, Director, Municipal)

El segundo aspecto concierne a una utilidad percibida en el largo plazo. En particular, los actores educativos manifiestan que quienes eligen y acceden a la oferta de excelencia intentan incrementar sus posibilidades de proseguir estudios en la educación superior:

Creo que no están reñidas [las tipologías de oferta], pero aquí [la oferta de excelencia académica], va el padre que aspira que su hijo sea un profesional en el futuro. Entonces está preparándole el camino hacia ese futuro, ya que aquí tendrá todas las herramientas académicas para salir adelante [...] (E14, Directora, Municipal)

Este fragmento, junto con otros que exacerban en alusiones a resultados en la PSU, ilustra la creencia relacionada con que el aseguramiento de resultados es un mecanismo instrumental que permite acceder a la universidad. La creencia descrita reafirma la segmentación de la oferta escolar, en donde algunas familias intencionan búsquedas orientadas a generar ganancias secundarias, que evidencian la ilusión de aumentar sus posibilidades de movilidad social y/o a mantener su posición en la estructura social: 
[...] Son técnicos [los posibles usuarios de una escuela de excelencia], [...] que tienen el mito de la educación como medio de ascenso social y dicen " yo no tengo grandes condiciones económicas, pero sé que esta cuestión [la educación] lo logra [la movilidad social]", y hay una comunidad educacional que está muy comprometida con la cuestión, porque es lo que buscan vender, "la escuela de excelencia académica", que además es como un proceso de ascenso [...] (E12, Directivo institucional, Particular subvencionado)

\section{Oferta de Servicios}

\section{Una oferta basada en el déficit}

Como se anticipó, esta tipología de la oferta escolar tiene su origen en la carencia del reconocimiento estatal denominado "excelencia académica". Siguiendo la lógica y creencias de los participantes, aquellos centros escolares que recurren a estos afiches exhiben un déficit de logros en el plano académico, que intentan compensar a través de la promoción de una amplia gama de servicios:

[...] la excelencia académica nadie la va a ocultar. El que la tiene la va a publicitar y la va a ofrecer. Entonces, el otro no la tiene y va a ofrecer lo que tiene adentro, va a ofrecer otras cosas [...] (G1, Apoderadas, Municipal)

Desde la perspectiva de los apoderados y directivos, la lógica compensatoria en que se funda esta modalidad de la oferta escolar tendría correspondencia con las características del estudiantado que accede a este tipo de escuelas:

[...] porque esto te está diciendo, que si tú no resultas acá [se refiere a la excelencia], tú te vas, si no tienes una cantidad de nota te puedes ir [...] en cambio acá [en la escuela con oferta de servicios], ese niño que no tiene logro, aquí tratamos de apoyarlo para sacarlo adelante [...] (E6, Directora, Municipal)

La cita expuesta nos permite ilustrar la lógica del déficit, pues este tipo de escuela acogería en sus aulas a quienes no han sido atendidos en las instituciones conocidas como "academicistas", es decir, estudiantes que no se ajustan al perfil de una escuela que ostenta el rótulo de "excelencia académica". Esta correspondencia, entre un cierto tipo de escuela, una forma de marketing y un público objetivo, refuerza las conjeturas sobre la segmentación vertical que ordena la oferta escolar en el contexto de los mercados locales. Por lo tanto, el tipo de escuela que utiliza un afiche con múltiples servicios tendría una posición de mercado baja respecto de aquellas que disponen de "excelencia académica", situación que define su público como carente de las principales características del "consumidor de la excelencia".

Sin perjuicio de lo planteado, los participantes no expresaron una desvalorización acerca de esta propuesta. Por el contrario, sus opiniones le añaden valor, resignificándola como una 
propuesta inclusiva, no sólo por la receptividad sino también por la apertura a formas de enseñanza distintas a la "academicista", en marcada oposición a la oferta de excelencia académica, caracterizada como selectiva:

[...] yo veo esto como una educación mucho más focalizada en lo integral, el hecho que se declare que tiene SEP también ya está marcando que es un tipo de alumno particular, tiene PIE, claro, entonces es más amplio el abanico de alumnos que está dispuesto a recibir o más bien no hay exclusión, hay inclusión, es más inclusiva la educación [...] (E8, Directora, Municipal)

[...] Acá [afiche de oferta de servicios], como madre una puede ver que ofrece "psicólogo", "fonoaudiólogo", entonces está dirigido a niños que pueden tener problemas de lenguaje o de aprendizaje, y acá lo podrían integrar, en cambio acá [afiche de oferta de excelencia académica] es difícil que entreguen el mismo apoyo. (G3, Apoderadas, Particular Subvencionado)

En síntesis, la oferta de servicios representa escuelas emplazadas en la zona baja de sus mercados locales y que desarrollan una propuesta educativa que, resignificada en términos de inclusión, se especializa en cubrir múltiples necesidades de estudiantes afectados por distintas carencias educativas y socioeconómicas.

\section{Una escuela para todos: el consumidor de servicios}

Siguiendo las descripciones propuestas por los participantes, es posible identificar que el público objetivo de la oferta de servicios remite a estudiantes que adolecen de las características requeridas en los ambientes educativos catalogados como de "excelencia". Por ende, la "oferta inclusiva" se constituye en la opción de "todos" quienes, por características económicas, conductuales o académicas, no acceden a la "excelencia":

[...] yo creo que este es un colegio que está destinado a niños con necesidades, porque tiene SEP, qué sé yo, que son niños, cualquier niño, muy inclusivo. Y esto, está destinado a niños que son academicistas. Aquí [oferta de servicios] va todo tipo de niños y ahí [oferta de excelencia académica] van niños que tienen un buen resultado [académico] [...] (E11, Directora, Particular Subvencionado)

El fragmento escogido ilustra la dicotomía de las tipologías de oferta, ya que la participante identifica una escuela para "niños con necesidades" y otra para "niños academicistas". Dicha escisión refrenda que el público objetivo de la oferta de servicios se caracteriza por determinados déficits y carencias. En este marco, es preciso dilucidar cuáles son las características específicas que los participantes asumen respecto de este público objetivo. Una primera caracterización refiere a estudiantes que requieren la labor del PIE para atender necesidades educativas especiales. En los relatos recopilados, el PIE y sus profesionales constituyen un servicio educativo altamente demandado por familias cuyos hijos presentan dificultades: 
[...] hay padres que sí [intencionan la búsqueda de escuelas que disponen de PIE]... porque también hay colegios donde los especialistas los derivan a colegios que tengan PIE, para ser atendido en la necesidad que tenga el niño [...] (E9, Director, Municipal)

La segunda característica concierne a la clase social de los estudiantes y sus familias. A diferencia del público objetivo de" excelencia académica" no necesariamente vinculado a un grupo socioeconómico concreto, en este caso surgen asociaciones con una clase social baja o clase trabajadora. En efecto, según los participantes, el usuario típico de estas escuelas proviene de una clase baja, de escasos recursos económicos:

Esto lo veo [afiches de múltiples servicios], todos los días en Independencia [comuna de Santiago], en los colegios que están en el eje Independencia, en que van inmigrantes, enfocados ahí, a familias que no son profesionales ni que tienen estudios superiores, pero que buscan que sus hijos estudien en algún colegio. Pero son como más de esas características, una clase mucho más baja [...] (E12, Directivo institucional, Particular subvencionado)

Como lo indican las citas expuestas, esta creencia no se basa en prejuicios, sino en marcadores visuales concretos como, por ejemplo, el rótulo de la SEP, que informa de la presencia de alumnos prioritarios:

[...] tiene un plan de la Ley SEP, muy importante y todo lo que ahi están vendiendo son elementos financiados por Ley SEP, por lo tanto, tienen un alto nivel de estudiantes prioritarios, y por tanto todo lo que colocan acá, los beneficios que están formulando, son beneficios para gente que tiene necesidades [afiches de múltiples servicios] [...] (E12, Directivo institucional, Particular subvencionado)

Considerando esta descripción socioeconómica del público y su caracterización como familias de clase trabajadora, desde la voz de los hablantes adquiere sentido la promoción de servicios específicos, como los talleres extraprogramáticos y la JEC:

Si no ofrecemos un taller donde los niños puedan hacer deportes o danza o huerto, como tenemos acá, al niño no lo podríamos integrar bien ¿cierto? Nos preocupamos de eso y sabemos además que trabajamos solos, porque estos padres no vienen aquí a la escuela [...] (E6, Directora, Municipal)

Por último, en el relato de los participantes también cabe la posibilidad que esta modalidad de marketing esté dirigida a familias que no adhieren a la propuesta academicista. Si bien, se trata de un perfil mucho menos nítido, este público buscaría formas de enseñanza distintas a las tradicionales, habitualmente enfocadas en las asignaturas principales del currículo: 
[...] tiene talleres y otras cosas [la oferta de servicios], entonces los niños pueden aprender jugando. Lo que al menos a mi me gusta [...] Como que a mi hijo le gusta más aprender jugando, por eso me llama más la atención esta que tiene talleres, porque al de excelencia académica le da lo mismo esto, sé cómo funciona, entonces yo no enviaría a mi hija a un colegio así [de excelencia académica] (G2, Apoderadas, Municipal)

Resumiendo, el público objetivo de la oferta de servicios es amplio en sus características y requerimientos. No obstante, los actores participantes informan que habría dos características puntuales que pueden asociarse al consumidor de la oferta de servicios: la búsqueda de servicios que permiten atender necesidades educativas especiales y/o dificultades en el área del aprendizaje y un origen social ubicado en la clase baja o trabajadora.

\section{El valor agregado: incluir para superar el déficit}

Desde la óptica de los participantes, la oferta de servicios dispone de valor agregado en función de su potencial para generar inclusión socioeducativa y propender hacia la superación de los déficits, materiales e inmateriales, que afectan a sus usuarios.

Con más detalle, una de las características que se atribuye a la oferta de servicios es la de ser reconocida como un espacio de inclusión, el cual estaría orientado a admitir a todo el estudiantado, indistintamente de su procedencia social o habilidades académicas. Esta resignificación se expresa en la valoración por la mixtura social, que se asume como parte de la función pedagógica y social de la escuela:

[...] la idea [de la educación] es que mezcle todo, niños que les va bien, niños que les va mal, niños que les cuesta, niños que no hemos sabido cómo, porque "niños que les cuesta" es darles la responsabilidad a ellos; en el fondo no hemos sabido ayudarlos [...] porque aquí [afiches de múltiples servicios] va a haber de todo, diversidad y eso es lo bueno. Lo mismo en los aspectos sociales. Entonces cuando mezclo estudiantes que están allá, que tienen mucho dinero, con gente que tiene menos dinero, esa comunión va a generar un mayor entendimiento como sociedad completa [...] (E13, Directivo institucional, Particular subvencionado)

Por otra parte, los actores consultados sostienen que la oferta inclusiva se concretiza a través de una serie de servicios, programas y subvenciones, que permiten abordar diversos requerimientos y déficits del estudiantado. Dicha multiplicidad de servicios posibilita la atención especializada de quienes: tienen necesidades educativas especiales, no logran altos desempeños académicos, o cuyas familias buscan satisfacer intereses artísticos y recreacionales mediante talleres y que, eventualmente, proceden de grupos socioeconómicos bajos, siendo categorizados como prioritarios según la nomenclatura de la ley SEP. De esto se desprende el segundo valor agregado, que alude a la potencial capacidad de la oferta de servicios para propender hacia la superación de los déficits de su alumnado: 
[...] a cualquier apoderado le puede interesar que tengan un psicólogo en la escuela, que tengan un fonoaudiólogo, porque posiblemente "mi hijo necesite tal cosa" [...] que tengan Jornada Escolar Completa, porque "yo trabajo y necesito que este todo el día", "a mi hijo le gusta la danza, que sería bueno que pudiera participar en un taller", "mi hijo es súper retraído, entonces qué bueno que participe en un taller de fútbol", en una cosa recreativa [...] "mira es necesario que haga sus tareas con otros compañeros, mejor en la escuela, entonces que tenga una sala de computación también es interesante, aunque yo lo tengo en mi casa, pero si lo tienen que hacer en grupo mejor que lo haga en la escuela, tiene los recursos" [...] "no puedo yo llevarle la alimentación, entonces qué bueno que tenga alimentación” ¿te fijas? Todo esto, efectivamente es atrayente para el apoderado. (E5, Directora, Municipal)

Acá [la oferta de servicios], lo más seguro es que no ignoren lo académico, pero aquí venden más la infraestructura, los talleres, porque hay padres a los que les gusta más el deporte, el arte [...] porque su centro es que el niño sea más feliz [...] hoy en día las casas son pequeñas y aqui [en la escuela] pueden encontrar espacio para la recreación y los padres tienen poco tiempo por el trabajo, entonces la escuela suple todo eso con talleres y salidas pedagógicas [...] (E14, Directora, Municipal)

Como lo enuncian las directoras citadas, cada servicio promocionado en estos afiches cubre necesidades específicas, materiales e inmateriales, que pueden aquejar a segmentos desventajados de la sociedad. Aquí emerge la imagen de la escuela como entidad social y su trascendente rol asistencial para con algunos grupos sociales, que en estos relatos es tan relevante como su rol netamente educativo. Consecuentemente y en concordancia con la caracterización de su público objetivo, esta oferta educativa permitiría subsanar diversas carencias de sus usuarios, en una dinámica casi clínica en que la escuela "remedia" ciertos déficits de origen como, por ejemplo, el escaso capital cultural o las limitaciones económicas.

\section{Consideraciones finales}

En la investigación aquí expuesta, nos propusimos explorar la producción de subjetividades que podrían configurar y justificar la segregación escolar en Chile. Con este objetivo, se realizó un uso adaptado de los "juegos de clasificación” de la Sociología Pragmática, lo cual requirió identificar afiches de publicidad exterior representativos de escuelas ubicadas en una zona urbana-metropolitana, para luego indagar en la interpretación sociocultural de directivos y familias sobre el mentado material publicitario. Cabe recordar que, en esta investigación, los afiches han sido comprendidos como fabricaciones, es decir, artefactos culturales que representan versiones de las escuelas y se fundan en subjetividades que otorgan sentido a su puesta en acto (Ball, 2000). 
Los datos recopilados evidencian dos unidades semánticas, las que, en términos concretos, refieren a tipologías de escuelas, distinguibles por la orientación de su oferta y público objetivo. De manera más detallada, es factible afirmar que el carácter estable y coherente de los relatos analizados revela esquemas mentales compartidos entre los participantes al momento de cualificar los afiches, a pesar de las diferencias en cuanto a roles y origen institucional. Estos esquemas mentales evidencian que el material gráfico fue interpretado como "escuelas tipo" que los actores reconocen y caracterizan a partir de sus experiencias cotidianas en el mercado escolar; a su vez, dichos esquemas, incorporan justificaciones normativas acerca de los propósitos y el público correspondiente a cada tipo de oferta educativa. De este modo, en una tipología, los sentidos subjetivos aluden a una escuela que promociona logros académicos y busca atraer estudiantes de alto desempeño, mientras en la otra, remiten a una escuela que ofrece servicios asistenciales y extrapedagógicos para usuarios en situación de déficit, ya sea en lo educativo o en lo socioeconómico.

Por sobre la cuestión de la veracidad y efectividad del material publicitario, interesó analizar las disposiciones que los actores educativos revelan mediante la interpretación subjetiva de los afiches y su relación con la segregación escolar. A este respecto, las unidades semánticas descritas dan a conocer un sentido de reciprocidad entre las tipologías de escuela, las características de su oferta y público objetivo, cosificándose relatos que justifican procesos de autosegregación. Empero, considerando que la segregación se produce a partir de la incidencia de factores exógenos y endógenos a los sistemas escolares, una comprensión profusa de los hallazgos obtenidos implica analizarlos, a lo menos, en dos niveles: la sociedad en que tienen ocurrencia y las dinámicas propias de un modelo de mercado escolar.

Como plantean Berger y Luckman (2008), el interés sociológico en cuanto al "conocimiento" se justifica por el hecho de su relatividad social. En este sentido, resulta imprescindible posicionar los hallazgos en el contexto de la sociedad chilena, un espacio social caracterizado históricamente por altos niveles de segregación residencial y una fuerte desigualdad, tanto en la distribución de ingresos como en el trato social (PNUD, 2016).

Los rasgos societales descritos conforman un soporte cultural que configura -a lo menos de manera parcial- las dinámicas de segregación reveladas mediante los resultados de esta investigación. Por un lado, las subjetividades referidas a la "Oferta de Excelencia Académica" se adecuan a un ideal meritocrático de carácter individualista que, influenciado por valores neoliberales y profundamente arraigado en amplios segmentos -bajos y mediosde la sociedad chilena, tiende a exacerbar las expectativas en el esfuerzo y las capacidades individuales de los actores, a la vez que fija en el acceso a "mejores" oportunidades educativas el principal factor de movilidad ascendente (Barozet; Mac-Clure, 2014; MacClure et al., 2015; PNUD, 2016). Por otro lado, la "Oferta de Servicios" y sus subjetividades evidencian un clivaje que, entre otros aspectos, se relaciona con el origen socioeconómico de los actores, especialmente aquellos de los estratos bajo y medio bajo. En torno a esto último, éstas dinámicas de segregación escolar tienen a la base los altos niveles de segregación residencial existentes en las grandes zonas urbanas metropolitanas de Chile, las que, si bien son incrementadas por mecanismos de mercado como el cobro de tarifas y la libre elección 
(Valenzuela; Bellei; De los Ríos, 2014; Gutiérrez, 2019), se hallan fundamentadas en racionalidades vinculadas a la clase social de procedencia, como lo documenta la investigación cualitativa reciente sobre elección de escuela para el caso chileno (e.g. Rojas; Falabella; Leyton, 2016; Bellei et al., 2018).

Sin perjuicio de lo expuesto, también resulta pertinente analizar los hallazgos en función de las dinámicas propias de un modelo de mercado escolar, que en este caso nacional corresponde a un formato radical con cuarenta años de aplicación ininterrumpida. Desde esta óptica, las interpretaciones de los actores educativos ilustran una división en nichos de mercado, evidenciable en los propósitos y tipo de público atribuido a cada una de las ofertas representadas en los afiches. En consecuencia, esta segmentación del mercado deviene en un impulso hacia la segregación escolar que, en términos concretos, se cosifica en relatos que tienden a una ontologización de la reciprocidad entre ciertas tipologías de escuelas y perfiles de estudiantes.

La dinámica descrita no se asemeja a lo pronosticado por los proponentes del mercado, mas tampoco puede comprenderse como un "efecto colateral" sino como los "efectos prácticos o pragmáticos" de los mercados escolares en un contexto socioeducativo concreto. Efectivamente, los defensores de los mercados suponían que los proveedores educacionales, tanto públicos como privados, competirían para atraer a las familias con el fin último de acceder al voucher estatal, razón por la cual diversificarían sus proyectos educativos para atraer y fidelizar las preferencias de variadas audiencias, a la vez que incrementarían sostenidamente sus resultados de aprendizaje para evitar que las familias hagan uso de su opción de salida (Chubb; Moe, 1990; Friedman, 1997). Más adelante en el tiempo se han reconocido las insuficiencias de este modelo original, añadiéndose mecanismos de control y sanción que buscan direccionar la "calidad" de la enseñanza de las escuelas, y que en la sección teórica hemos denominado modelo de cuasi-mercado performativo o basado en el desempeño (Ball, 2000; Felouzis; Maroy; Van Zanten, 2013).

Empero, los hallazgos de este estudio ilustran que, desde la subjetividad de los actores, el modelo escolar consolidado en Chile y sus supuestos teóricos tienden a ser recontextualizados por los actores, siendo interpretados y puestos en práctica de manera tal que se establecen nichos de mercado en base a características personales y/o sociales de los estudiantes. De este modo, directivos y familias reconocen que en sus mercados locales algunos centros educativos desarrollan dinámicas de competencia de segundo orden, es decir, estrategias de captación de estudiantes de origen socioeconómico aventajado, disciplinados y de alto desempeño, asociados a la "Oferta de Excelencia Académica"; mientras que otras escuelas, ubicadas en la zona baja de sus mercados locales, tienden a elaborar una estrategia de captación dirigida a la amplia diversidad de estudiantes que no se ajustan al perfil descrito previamente, asemejándose a una dinámica competitiva de primer orden y que en este caso se vincula con la "Oferta de Servicios". Esta segmentación es comprensible en un cuasimercado performativo, ya que en este modelo la pervivencia de las escuelas depende de dos aspectos: el desempeño medido a través de pruebas estandarizadas y la asistencia promedio de estudiantes. 
A modo de conclusión, los hallazgos de este estudio ilustran el despliegue de relatos sobre la justificación y aceptación de dinámicas de segregación escolar, las cuales pueden entenderse como el "efecto práctico o pragmático" de un modelo de mercado escolar consolidado en una sociedad caracterizada históricamente por elevados niveles de segregación y desigualdad. En definitiva, las presiones del mercado impulsan a los proveedores a diseñar estrategias de captación que poca relación tienen con procesos pedagógicos, mientras los padres intentan acceder a la mejor opción dentro de sus limitaciones socioeconómicas y personales. Dichas subjetividades pueden comprenderse como la expresión de una racionalidad limitada (Ben-Porath, 2009), la cual supone que toda acción racional, ya sea con arreglo a fines o a valores, no ocurre de forma pura e independiente, sino que, por el contrario, siempre es la resultante de un imbricado proceso de ajuste a la realidad en que se conflictúan diversas restricciones materiales, contextuales e idiosincráticas.

En el marco de este análisis, es menester abordar algunas consideraciones metodológicas que se desprenden para la investigación futura. Aun cuando el material publicitario estaba supeditado a las dos Clases de afiches identificadas con una técnica de estadística multivariable, el uso adaptado de los "juegos de clasificación" demostró un importante potencial para captar los significados atribuidos a las fabricaciones que se elaboran en el marco del mercado escolar, destacándose la alineación semántica registrada en las opiniones respecto de cada tipología de afiches, aspecto que dota de consistencia los hallazgos de esta investigación cualitativa. Consiguientemente, este dispositivo metodológico permitió ilustrar el modo en que los distintos participantes enuncian los principios de valía de las fabricaciones expuestas, evidenciándose que el juicio de los actores no está basado en los principios oficialmente proclamados, sino que, en diferentes principios encubiertos, enraizados en subjetividades sociales que ameritan una mayor atención desde la investigación social de las políticas educativas y sus efectos prácticos.

$\mathrm{Al}$ comenzar este reporte de investigación enfatizamos la importancia que adquiere el desarrollo de sistemas educacionales inclusivos, tanto para garantizar una equitativa distribución de las oportunidades educativas como para aportar a la cohesión social. No obstante, los modelos de mercado educativo, de creciente difusión en la actualidad, generan efectos en un sentido contrario y, como lo ilustran los resultados de este estudio, la potencia prescriptiva de sus mecanismos favorece la producción de subjetividades que aceptan y/o justifican las dinámicas de segregación. Así, las subjetividades analizadas en este estudio revelan que en Chile parece haberse legitimado una ominosa cultura de la segregación escolar, cuya reversión no dependerá sólo de cambios profundos en las políticas escolares, sino también de políticas multisectoriales que favorezcan la sociabilidad pluriclasista y neutralicen las fuertes tendencias hacia la privatización y "guetificación" de los grupos sociales. 


\section{Notas:}

1. Estas refieren a la Ley de Subvención Escolar Preferencial (SEP) de 2008, Ley General de Educación (LGE) de 2009, y la Ley de Aseguramiento de la Calidad de la Educación (SAC) de 2011.

2. Traducción propia.

3. Sigla de Jornada Escolar Completa, programa estatal destinado a extender la jornada escolar.

4. Sigla de Programa de Integración Escolar, programa de subsidio estatal dirigido a la atención de estudiantes con necesidades educativas especiales.

5. Sigla de Subvención Escolar Preferencial, subsidio estatal incrementado para la atención de estudiantes en situación socioeconómica vulnerable, denominados prioritarios y preferentes.

6. Los afiches se presentan editados, cubriéndose imágenes de estudiantes y símbolos institucionales, como nombres e insignias.

7. Sigla de Sistema Nacional de Medición de la Calidad Educativa, consistente en una evaluación estandarizada del aprendizaje en las asignaturas de Lenguaje y Comunicación; Matemática; Ciencias Naturales; Historia, Geografía y Ciencias Sociales e Inglés. Las pruebas del SIMCE se aplican censalmente en $2^{\circ}, 4^{\circ}, 6^{\circ}, 8^{\circ}$ básico, y II medio, siguiendo un Plan de Evaluaciones (Fuente: https://www.agenciaeducacion.cl/evaluaciones/que-es-el-simce/ ).

8. Sigla de Prueba de Selección Universitaria.

9. Sigla de Sistema Nacional de Evaluación de Desempeño, cuya aplicación deriva en el reconocimiento denominado "Excelencia Académica".

\section{Referências}

SOBRENOME DO AUTOR, Prenomes do autor por extenso e intermediários abreviados. Título: subtítulo. Edição. Local de publicação: Editora, ano.

SOBRENOME DO AUTOR, Prenomes do autor por extenso e intermediários abreviados. Título: subtítulo. Edição. Local de publicação: Editora, ano. Disponível em: <http://www.endereco.com.br>. Acesso em: 04 jan. 2021.

AINSCOW, Mel; BOOTH, Tony; DYSON, Alan. Improving schools, developing inclusion. Londres: Routledge, 2006.

BALL, Stephen. Performativities and fabrications in the education economy: towards the performative society. Australian Educational Researcher, v. 27, n. 2, p. 1-24, 2000.

BAROZET, Emmanuelle; MAC-CLURE, Oscar. Nombrar y Clasificar: Aproximación a una Epistemología de las Clases Sociales. Cinta Moebio, n. 51, p. 197-215, 2014.

BELLEI, Cristián et al. Elección de escuela en sectores populares: Estado, mercado e integración social. Revista Austral de Ciencias Sociales, n. 31, p. 95-110, 2016.

BELLEI, Cristián et al. The production of socio-economic segregation in Chile's Education System. In: BONAL, Xavier; BELLEI, Cristián (Ed.). Understanding school segregation. Patterns, causes and consequences of spatial inequalities in education. London: Bloomsbury, 2018. P. 221-240.

BEN-PORATH, Sigal. School choice as a bounded ideal. Journal of Philosophy of Education, n. 43, v. 4, p. 527-544, 2009.

BERGER, Peter; LUCKMAN, Thomas. La construcción social de la realidad. Buenos Aires: Amorrortu, 2008. 
BOLTANSKI, Luc. On Critique. A Sociology of Emancipation. Cambridge: Polity Press, 2011.

BOLTANSKI, Luc; THÉVENOT, Laurent. Finding one's way in social space: a study based on games. Social Science Information, v. 22, n. 4-5, p. 631-680, 1983.

BAUM, Donald. The effectiveness and equity of public-private partnerships in education: A quasi-experimental evaluation of 17 countries. Education Policy Analysis Archives, v. 26, n. 105, 2018.

BONAL, Xavier; BELLEI, Cristián. The renaissance of school segregation in a context of globalization. In: BONAL, Xavier; BELLEI, Cristián (Ed.). Understanding school segregation. Patterns, causes and consequences of spatial inequalities in education. London: Bloomsbury, 2018. P. 1-26.

BONAL, Xavier; VERGER, Antoni; ZANCAJO, Adrián. Making Poor Choices? Demand Rationalities and School Choice in a Chilean Local Education Market. Journal of School Choice, v. 11, n. 2, p. 258-281, 2017.

CANALES, Manuel; BELLEI, Cristián; ORELLANA, Víctor. ¿Por qué elegir una escuela privada subvencionada? Sectores medios emergentes y elección de escuela en un sistema de mercado. Estudios Pedagógicos, v. 42, n. 3, p. 89-109, 2016.

CARRASCO, Alejandro; GUNTER, Helen. The "private" in the privatisation of schools: the case of Chile. Educational Review, v. 71, n. 1, p. 67-80, 2019.

CHUBB, John; MOE, Terry. Politics, Markets and America's Schools. American Political Science Review, v. 82, n. 2, p. 1065-1087, 1990.

CONDE, Fernando. Introducción al análisis sociológico del sistema de discursos. In: GARCÍA, Manuel; ALVIRA, Francisco; ALONSO, Luis; ESCOBAR, Modesto (Comps.). El análisis de la realidad social. Métodos y técnicas de investigación (4ta Ed.). Madrid: Editorial Alianza, 2015. P. 641-663.

CONTRERAS, Dante; BUSTOS, Sebastián; SEPÚLVEDA, Paulina (2010). When schools are the ones that choose: The effect of screening in Chile. Social Science Quarterly, 91(5), p. 1349-1368.

CÓRDOBA, Claudia. La elección de la escuela en sectores pobres. Resultados de un estudio cualitativo. Psicoperspectivas, v. 3, n. 1, p. 56-67, 2014.

CORNEJO, Rodrigo. Políticas y reformas escolares: el experimento educativo chileno y su evolución. In: RUIZ-SCHNEIDER, Carlos; REYES, Leonora; HERRERA, Francisco (Ed.). Privatización de lo público en el sistema escolar. Chile y la agenda global de educación. Santiago: LOM Ediciones, 2018. P. 237-263.

CORNEJO, Rodrigo et al. Las prescripciones del trabajo docente en el nuevo marco regulatorio de políticas educativas en Chile. Psicoperspectivas, v. 14, n. 2, p. 72-83, 2015.

CRESWELL, John. Research design qualitative, quantitative and mixed method approaches 4 th edition. California: SAGE Publications, Inc., 2014.

DUK, Cynthia; MURILLO, Francisco Javier. Segregación escolar y meritocracia. Revista Latinoamericana de Educación Inclusiva, v. 13, n. 1, p. 11-13, 2019.

DUPRIEZ, Vincent; DUMAY, Xavier. Inequalities in school systems: effect of school structure or of society structure? Comparative Education, v. 42, n. 2, p. 243-260, 2006.

EPPLE, Dennis; ROMANO, Richard. Competition between Private and Public Schools, Vouchers, and PeerGroup Effects. The American Economic Review, v. 88, n. 1, p. 33-62, 1998.

FELOUZIS, Georges; MAROY, Christian; VAN ZANTEN, Agnès. Les marchés scolaires. Sociologie d'une politique publique d'éducation. Paris: Presses Universitaires de France, 2013.

FINCH, Holmes; BRONK, Kendall Cotton. Conducting Confirmatory Latent Class Analysis Using Mplus. Structural Equation Modeling: A Multidisciplinary Journal, v. 18, n. 1, p. 132-151, 2011.

FRIEDMAN, Milton. Public Schools: Make Them Private. Education Economics, v. 5, n. 3, p. 341-344, 1997.

GUTIÉRREZ, Gabriel. Fifteen Years of Socioeconomic Segregation in Chile: Trends over Two Periods of Educational Policies. University College London, Institute of Education. Working Paper, 2019. 
GUBBINS, Verónica. La experiencia subjetiva del proceso de elección de establecimiento educacional en apoderados de escuelas municipales de la Región Metropolitana. Estudios Pedagógicos, v. 39, n. 2, p. 165177, 2013.

IBÁÑEZ, Jesús. Más allá de la sociología. El grupo de discusión, teoría y práctica. Madrid: Siglo Veintiuno Editores, 1979.

INZUNZA, Jorge et al. Public education and student movements: the Chilean rebellion under a neoliberal experiment. British Journal of Sociology of Education, v. 40, n. 4, p. 490-506, 2019.

JABBAR, Huriya. Every Kid Is money market-like competition and school leader strategies in New Orleans. Educational Evaluation and Policy Analysis, v. 37, n. 4, p. 638-659, 2015.

KRÜGER, Natalia. La segregación por nivel socioeconómico como dimensión de la exclusión educativa: 15 años de evolución en América Latina. Education Policy Analysis Archives, Arizona, v. 27, n. 8, 2019.

LUBIENSKI, Christopher. Marketing Schools: Consumer goods and competitive incentives for consumer information. Education and Urban Society, v. 40, n. 1, p. 118-114, 2007.

MAC-CLURE, Oscar et al. La clase media clasifica a las personas en la sociedad: Resultados de una investigación empírica basada en juegos. Psicoperspectivas, v. 14, n. 2, p. 4-15, 2015.

MAXWELL, Joseph. Qualitative research design an interactive approach, $3^{\circ}$ Edition. California: SAGE Publications, Inc., 2013.

MICKELSON, Roslyn; NKOMO, Mokubung. Integrated Schooling, Life Course Outcomes, and Social Cohesion in Multiethnic Democratic Societies. Review of Research in Education, v. 36, p. 197-238, 2012.

MIZALA, Alejandra; TORCHE, Florencia. Bringing the schools back in: the stratification of educational achievement in the Chilean voucher system. International Journal of Educational Development, v. 32, p. 132-144, 2012.

MURILLO, Francisco Javier; MARTÍNEZ-GARRIDO, Cynthia. Estimación de la magnitud de la segregación escolar en América Latina. Revista Internacional de Investigación en Educación, v. 9, n. 19, p. 11-30, 2017.

ORGANIZACIÓN PARA LA COOPERACIÓN Y EL DESARROLLO ECONÓMICOS [OCDE]. Evaluaciones de políticas nacionales de educación. Educación en Chile. Santiago: OCDE, Fundación SM, 2017.

OYARZÚN, Cristian. "La escuela que busco, la escuela que ofrezco": Contenidos y racionalidades de la oferta educativa del mercado escolar chileno. Archivos Analíticos de Políticas Educativas; v. 29, n. 13, p. 1-39, 2021. https://doi.org/10.14507/epaa.29.4992

PARCERISA, Lluís; FALABELLA, Alejandra. La consolidación del Estado evaluador a través de políticas de rendición de cuentas: Trayectoria, producción y tensiones en el sistema educativo chileno. Education Policy Analysis Archives, v. 25, n. 89, 2017.

PROGRAMA DE NACIONES UNIDAS PARA EL DESARROLLO [PNUD]. Desiguales. Orígenes, cambios y desafíos de la brecha social en Chile. Santiago: PNUD, 2017.

ROJAS, María Teresa; FALABELLA, Alejandra; LEYTON, Daniel. Madres de clases medias frente al mercado educativo: decisiones y dilemas. In: CORVALÁN, Javier; CARRASCO, Alejandro; GARCÍAHUIDOBRO, Juan Eduardo (Ed.). Mercado escolar y oportunidad educacional. Libertad, diversidad y desigualdad. Santiago: Ediciones UC, 2016. P. 233-266.

SANTOS, Humberto; ELACQUA, Gregory. Socioeconomic school segregation in Chile: parental choice and a theoretical counterfactual analysis. Cepal Review, n. 19, p. 123-137, 2016.

SISTO, Vicente. Inclusión "a la chilena": La inclusión escolar en un contexto de políticas neoliberales avanzadas. Archivos Analíticos de Políticas Educativas, v. 27, n. 23, 2019.

UNITED NATIONS EDUCATIONAL SCIENTIFIC AND CULTURAL ORGANIZATION [UNESCO]. 
Educación para los Objetivos de Desarrollo Sostenible. Objetivos de aprendizaje. Paris: UNESCO, 2017.

VALENZUELA, Juan Pablo; BELLEI, Cristián; DE LOS RÍOS, Danae. Socioeconomic school segregation in a market-oriented educational system. The case of Chile. Journal of Education Policy, v. 29, n. 2, p. 217 241, 2014.

VERGER, Antoni; ZANCAJO, Adrián; FONTDEVILA, Clara. La economía política de la privatización educativa: políticas, tendencias y trayectorias desde una perspectiva comparada. In: RUIZ-SCHNEIDER, Carlos; REYES, Leonora; HERRERA, Francisco (Ed.). Privatización de lo público en el sistema escolar. Chile y la agenda global de educación. Santiago: LOM Ediciones, 2018. P. 35-58.

ZANCAJO, Adrián. Educational providers in the marketplace: Schools' marketing responses in Chile. International Journal of Educational Research, v. 88, p. 166-176, 2018.

ZANCAJO, Adrián; VERGER, Antoni y BONAL, Xavier. Mercados educativos y segmentación de la oferta escolar: efectos sobre las desigualdades educativas en Chile. Revista Témpora, v. 17, p. 11-30, 2014.

\section{Correspondência}

Cristian Oyarzún Maldonado: Licenciado en Psicología por la Universidad de Santiago de Chile y Magíster en Ciencias Sociales por la Universidad de Chile. Actualmente es estudiante del Doctorado en Psicología de la Universidad de Chile.

E-mail: cristian.oyarzunm@usach.cl

Orcid: https://orcid.org/0000-0003-4811-8633

Rodolfo Soto González: Licenciado en Psicología por la Universidad de Santiago de Chile y Magíster en Psicología Educacional por la Universidad de Chile. Actualmente es estudiante del Doctorado en Psicología Educativa de la Universitat de Barcelona.

E-mail: rodolfo.soto@usach.cl

Orcid: https://orcid.org/0000-0003-3061-6036

Texto publicado em Currículo sem Fronteiras com autorização dos autores. 